\title{
Diagnostic Performance and Reliability of Non-Enhanced Imaging Characterization Quotients for the Differentiation of Infectious and Malignant Pulmonary Nodules in Hematological Patients Using 3T MRI
}

\author{
Diagnostische Genauigkeit und Zuverlässigkeit nativer \\ Bildgebungscharakterisierungsquotienten zur Differenzierung \\ infektiöser und maligner pulmonaler Herdbefunde in \\ hämatologischen Patienten im 3T-MRT
}

\section{Authors}

Sebastian Niko Nagel', Damon Kim', Tatjana Wylutzki ${ }^{1}$, Ingo G. Steffen ${ }^{1}$, Stefan Schwartz ${ }^{2}$, Tobias Penzkofer ${ }^{1}$, Bernd Hamm¹, Thomas Elgeti ${ }^{1,3}$

Affiliations

1 Department of Radiology, Charité - Universitätsmedizin Berlin, Germany

2 Department of Hematology and Oncology, Charité - Universitätsmedizin Berlin, Germany

3 Department of Nuclear Medicine, Charité Universitätsmedizin Berlin, Germany

Key words

thorax, diagnostic radiology, infection, lymphoma, MR imaging

received 28.03.2019

accepted 19.08.2019

Bibliography

DOI https://doi.org/10.1055/a-1005-7424

Published online: 24.10.2019

Fortschr Röntgenstr 2020; 192: 327-334

(c) Georg Thieme Verlag KG, Stuttgart · New York

ISSN 1438-9029

Correspondence

Dr. Sebastian Niko Nagel

Department of Radiology, Charité-Universitätsmedizin Berlin, Hindenburgdamm 30, 12203 Berlin, Germany

Tel.: + 49/30/450627733

sebastian.nagel@charite.de

\section{ZUSAMMENFASSUNG}

Ziel Beurteilung der diagnostischen Genauigkeit und Reliabilität nichtkontrastmittelverstärkter Charakterisierungsquotienten (engl. „non-enhanced imaging characterization quotients“, kurz NICQs) in der Magnetresonanztomografie (MRT) zur differenzialdiagnostischen Einordnung pulmonaler Herdbefunde in hämatologischen Patientinnen und Patienten.
Material und Methoden Es wurden insgesamt 83 Läsionen in 45 konsekutiven hämatologischen Patienten analysiert (10 bakterielle Pneumonien, 16 Pilzpneumonien, 19 pulmonale Lymphom-Manifestationen). Das MRT-Protokoll bestand aus T2-gewichteten Single-Shot Fast-Spin-Echo-(FSE) und T1-gewichteten Gradientenecho (GRE)-Sequenzen. Der jeweils T2-basierte T2-NICQ mean und T2-NICQ ${ }_{90 t h}$ wurde aus der Signalintensität der Läsion, der Muskulatur und des Fettgewebes errechnet ( $\left(\mathrm{SI}_{\text {Läsion }}-\mathrm{SI}_{\text {Muskulatur }}\right) /$ $\left.\left(S I_{\text {Fettgewebe }}-\mathrm{SI}_{\text {Muskulatur }}\right) * 100\right)$, der simple T1-basierte Quotient T1-Qmean aus der Signalintensität der Läsion und der Muskulatur ( $\mathrm{SI}_{\text {Läsion }} / \mathrm{SI}_{\text {Muskulatur }}$ ). Die Bildauswertung erfolgte durch einen Radiologen mit $>7$ Jahren und eine Radiologin mit 1 Jahr Erfahrung. Für die statistische Auswertung kamen der Kruskal-Wallis- oder Mann-Whitney-U-Test, die ReceiverOperating-Characteristic (ROC)-Analyse mit Berechnung der Area Under the Curve (AUC) sowie die Berechnung von Intraclass-Korrelationskoeffizienten (ICCS) zum Einsatz.

Ergebnisse Die Medianwerte beider T2-NICQs unterschieden sich signifikant zwischen infektiösen Veränderungen und Lymphom-Manifestationen im Allgemeinen (T2-NICQ ${ }_{\text {mean }}$ 20,33 vs. 10,14 ; T2-NICQ $_{90 \text { th }} 34,96$ vs. 25,52 ) sowie Pilzinfiltrationen und Lymphom-Manifestationen im Besonderen (T2-NICQ ${ }_{\text {mean }} 19,00$ vs. 10,14; T2-NICQ 90 th 34,49 vs. 25,25). Die AUCs auf Patientenebene für die T2-NICQs lagen dabei zwischen 0,73 und 0,79. Die ICCs betrugen mindestens $>0,85$, mit Ausnahme der Bewertung der Intrarater-Reliabilität des T2-NICQ90th $(0,79)$.

Schlussfolgerung Die diagnostische Leistung der T2-NICQs hinsichtlich der Differenzierbarkeit allgemeiner bzw. fungaler Infiltrate von pulmonalen Lymphom-Manifestationen ist angemessen. Die Intra- und Interrater-Übereinstimmung ist gut bis exzellent. Von daher erachten wir NICQs als hilfreich bei der differenzialdiagnostischen Aufarbeitung unklarer pulmonaler Herdbefunde in hämatologischen Patientinnen und Patienten. 


\section{Kernaussagen:}

- Nichtkontrastmittelverstärkte Charakterisierungsquotienten bieten einen schnellen und pragmatischen Ansatz für die Beurteilung pulmonaler Herde in hämatologischen Patientinnen und Patienten.

- Die diagnostische Leistung von nichtkontrastmittelverstärkten Charakterisierungsquotienten ist angemessen, um infektiöse und pilzpneumonische Infiltrate von Lymphom-Manifestationen zu unterscheiden.

- Nichtkontrastmittelverstärkte Charakterisierungsquotienten zeigen eine gute bis exzellente Intra- und InterraterReliabilität.

\section{ABSTRACT}

Purpose To evaluate the diagnostic performance and reliability of non-enhanced imaging characterization quotients (NICQs) derived from magnetic resonance imaging (MRI) in the differential diagnosis of pulmonary nodules in hematological patients.

Materials and Methods A total of 83 lesions in 45 consecutive hematological patients were analyzed (10 bacterial pneumonias, 16 fungal pneumonias, 19 pulmonary lymphoma manifestations). The MRI protocol included T2-weighted single-shot fast spin echo (FSE) and T1-weighted gradient echo (GRE) sequences. T2-based T2-NICQ ${ }_{\text {mean }}$ and T2-NICQ ${ }_{90 \text { th }}$ were calculated from signal intensities measured in the lesion, muscle, and fat $\left(\left(\mathrm{SI}_{\text {Lesion }}-\mathrm{SI}_{\text {Muscle }}\right) /\left(\mathrm{SI}_{\text {Fat }}-\mathrm{SI}_{\text {Muscle }}\right) * 100\right)$, and simple T1-based $T 1-Q_{\text {mean }}$ from signal intensities of the lesion and muscle $\left(\mathrm{SI}_{\text {Lesion }} / \mathrm{SI}_{\text {Muscle }}\right)$. Images were read by one radiologist with $>7$ years and one with 1 year of experience. For statistical evaluation the Kruskal-Wallis or Mann-Whitney U-test, receiver operating characteristic (ROC) analysis with calculation of areas under the curve (AUC), and intraclass correlation coefficients (ICCS) were used.

Results Medians of T2-NICQs differed significantly when comparing infectious lesions and lymphoma manifestations in general (T2-NICQ 20.33 vs. 10.14; $\mathrm{T}_{\text {mean }}-\mathrm{NICQ}_{90 \text { th }} 34.96$ vs. 25.52) or fungal lesions and lymphoma manifestations in particular (T2-NICQ ${ }_{\text {mean }} 19.00$ vs. 10.14; T2-NICQ $_{90 \text { th }} 34.49$ vs. 25.25). The AUCs for T2-NICQs on the per-patient level ranged from 0.73 to 0.79 . ICCs were at least $>0.85$, except for intrarater testing of $\mathrm{T}_{2}-\mathrm{NICQ}_{90 \text { th }}(0.79)$.

Conclusion The overall diagnostic performance of T2-NICQs is adequate for differentiating infectious and fungal lesions from lymphoma manifestations. The results show good to excellent intra- and interrater agreement. We therefore consider NICQs helpful in the diagnostic workup of pulmonary nodules in hematological patients.

\section{Key points:}

- Non-enhanced Imaging Characterization Quotients provide a fast and pragmatic approach for assessing pulmonary lesions in hematological patients.

- The diagnostic performance of Non-enhanced Imaging Characterization Quotients is adequate for differentiating infectious and fungal infiltrates from lymphoma manifestations.

- Non-enhanced Imaging Characterization Quotients show good to excellent intra- and interrater agreement.

\section{Citation Format}

- Nagel SN, Kim D, Wylutzki T et al. Diagnostic Performance and Reliability of Non-Enhanced Imaging Characterization Quotients for the Differentiation of Infectious and Malignant Pulmonary Nodules in Hematological Patients Using 3T MRI. Fortschr Röntgenstr 2020; 192: 327-334

\section{Introduction}

The differential diagnosis of pulmonary findings can be a challenge for radiologists in hematological patients, especially when the distinction between an infection and pulmonary involvement of an underlying disease is required [1]. Morphologic features, such as the halo sign in invasive bronchopulmonary aspergillosis on computed tomography scans, can be of help, but are nonspecific [2, 3]. In addition, the results of other diagnostic procedures, such as the galactomannan test, may also be inconclusive. In a study by Cao et al., for instance, this test identified only $73.5 \%$ of patients with aspergillosis [4]. If the diagnosis remains unclear, appropriate treatment may be delayed, which is known to be associated with higher morbidity and mortality in the case of fungal infections [5, 6]. To establish the correct diagnosis, invasive diagnostic procedures such as bronchoscopic sampling may become necessary [7]. Taking these considerations into account, a fast and noninvasive diagnostic approach that helps in the diagnostic workup of unclear cases is desirable.
Magnetic resonance imaging (MRI) provides excellent soft-tissue contrast and different studies using either diffusion-weighted imaging (DWI) or dynamic contrast-enhanced imaging (DCE) showed that it can help to differentiate between benign and malignant pulmonary nodules [8-11]. However, these methods may not be suitable for patients who do not tolerate long examination times or who cannot receive intravenous contrast medium. Against this background, encouraging results have been obtained in a study using T1- and T2-weighted images acquired with a fast MRI protocol at $3 \mathrm{~T}$ and defining scaled signal intensities as nonenhanced imaging characterization quotients (NICQs) [12]: combining T2-NICQ 90 th with T1-Q mean yielded $77 \%$ sensitivity and $95 \%$ specificity to differentiate benign and malignant pulmonary nodules. The advantage of this approach lies in its simplicity, both in terms of image acquisition and image analysis. To the best of our knowledge, NICQs have not been assessed in a larger collective of hematological patients.

The aim of the present study was therefore twofold: first, to assess the diagnostic performance of NICQs in differentiating bacterial and fungal infections from lymphoma manifestations in he- 
matological patients and, second, to assess the reliability of NICQs in this setting.

\section{Patients and Methods}

\section{Patients}

The local ethics committee approved this prospective study (EA4/017/14). Written consent was obtained from all participants. The inclusion criterion was the presence of at least one solid pulmonary lesion in a recent, clinically indicated chest X-ray or computed tomography (CT) scan. Patients with general contraindications to MRI were excluded.

The EORTC/MSG diagnostic criteria [13] served as the standard of reference in fungal infections (at least "probable"), histopathologic proof in lymphomas. Response clearly attributable to treatment was considered the standard of reference if the aforementioned information was not available.

\section{MRI technique}

All MRI examinations were performed on a 3 T MRI scanner (Magnetom Skyra, Siemens Healthineers, Erlangen, Germany) using a scan time-optimized protocol by Nagel et al. that was already successfully tested in a similar setting $[12,14]$ and originally derived from Biederer et al. and Attenberger et al. [15, 16]. The following three sequences were acquired with a surface coil positioned on the chest: axial and coronal T2-weighted (T2w) single-shot fast spin echo sequences (TR/TE 500/27, flip angle 160, matrix $256 \times 320$, slice $5 \mathrm{~mm}$ ) and axial T1-weighted (T1w) gradient echo sequences (TR/TE 5.39/2.04, flip angle 9, matrix $180 \times 320$, slice $3 \mathrm{~mm}$ ), all using multiple breath-hold regimens.

\section{Image analysis}

All images were read independently by two radiologists with different levels of experience (S.N. with $>7$ years and T.W. with 1 year of MRI experience) and blinded to the clinical data. Regions of interest (ROIs) were drawn in the lesion, muscle, and fat on T2w images and in the lesion and muscle on T1w images using 3D Slicer (Version 4.8.1) [17]. The ROI within the lesion was drawn while omitting vessels and bronchi and with a distance of approx. 1-2 pixels from the edge in relation to the resolution of the MR images. At least one representative layer was chosen for the ROI, but if the lesion was well visible on multiple layers, then also multiple ROIs were allowed. Only ROIs with at least 10 voxels were considered for the final analysis. The ROIs in muscle and fat were placed as close as possible to the lesion and preferably at the same height in the phase-encoding direction. A sample set of ROls is shown in - Fig. 1.

To test for interrater reliability, S.N. and T.W. both read all datasets; to test for intrarater reliability, T.W. repeated the reading of the datasets from the first 19 consecutive patients. Details of the location of the lesions were available to correlate repeated readings.
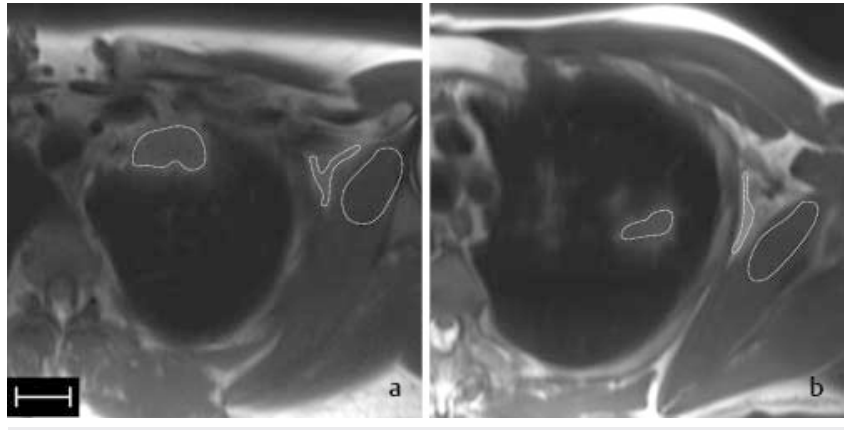

- Fig. 1 Example illustrating a set of regions of interest (ROIs) on T2-weighted images to calculate T2-NICQs. ROIs in muscle and fat were placed as close as possible to the lesion and preferably at the same height in the phase-encoding direction. Scale indicates $2 \mathrm{~cm}$. a 25 -year-old male patient with acute lymphoblastic leukemia and focal aspergillus infiltrate in the left upper lobe; $\mathrm{T}^{-}-\mathrm{NICQ}_{\text {mean }} 40.04$, T2-NICQ ${ }_{90 \text { th }}$ 74.78. b 42-year-old male patient with indolent follicular lymphoma and manifestation in the left upper lobe; T2-NICQ mean $10.04, \mathrm{~T}^{-}-\mathrm{NICQ}_{90 \text { th }}$ 24.02. T2-NICQ mean and T2-NICQ 90 th $\left(\left(\mathrm{SI}_{\text {Lesion }}-\mathrm{SI}_{\text {Muscle }}\right) /\left(\mathrm{SI}_{\text {Fat }}-\mathrm{SI}_{\text {Muscle }}\right) * 100\right)$.

- Abb. 1 Beispiel der Regions of Interest (ROIs) auf T2-gewichteten Bildern zur Berechnung von T2-NICQs. ROIs in Muskulatur und Fettgewebe wurden so nahe wie möglich an der Läsion und vorzugsweise in derselben Höhe der Phasenkodierrichtung platziert. Skala entspricht $2 \mathrm{~cm}$. a 25 Jahre alter männlicher Patient mit akuter lymphoblastischer Leukämie und fokalem Aspergillus-Infiltrat im linken Oberlappen; T2-NICQ mean 40,04, T2-NICQ 90 th 74,78. b 42jähriger männlicher Patient mit indolentem follikulärem Lymphom und Manifestation im linken Oberlappen; T2-NICQ $\mathrm{Nean}_{10}$ 10,04, T2$\mathrm{NICQ}_{90 \text { th }} 24,02$. T2-NICQ $\mathrm{Nmean}_{\text {und T2-NICQ }}$ uoth $\left(\left(\mathrm{SI}_{\text {Läsion }}-\mathrm{SI}_{\text {Muskulatur }}\right) /\right.$ $\left.\left(\mathrm{SI}_{\text {Fettgewebe }}-\mathrm{SI}_{\text {Muskulatur }}\right) * 100\right)$.

\section{Statistical analysis}

Scaled signal intensities, defined as T2-NICQ ${ }_{\text {mean }}$ and $\mathrm{T}_{2}-\mathrm{NICQ}_{90 \mathrm{th}}$, were calculated for $\mathrm{T} 2 \mathrm{w}$ images $\left(\left(\mathrm{SI}_{\text {Lesion }}-\mathrm{SI}_{\text {Muscle }}\right) /\left(\mathrm{SI}_{\mathrm{Fat}}-\mathrm{SI}_{\text {Muscle }}\right)\right.$ * 100 ) and as a simple quotient, $\mathrm{T} 1-\mathrm{Q}_{\text {mean }}$, for $\mathrm{T} 1 \mathrm{w}$ images $\left(\mathrm{SI}_{\text {Lesion }} / \mathrm{SI}\right.$ Muscle) $[12,18]$; calculations were done using the mean and $90^{\text {th }}$ percentile of signal intensity within the lesion for $\mathrm{T}_{2}-\mathrm{NICQ}_{\text {mean }}$ and T2-NICQ 90 th, respectively.

Categorical parameters are given as frequencies. All metric data were tested for normal distribution using the Shapiro-Wilk test. For normally distributed data, descriptive statistics are given as mean and standard deviation. If no normal distribution was found, the median and interquartile range are provided.

Statistical testing included the Kruskal-Wallis or Mann-Whitney U-test, receiver operating characteristic (ROC) analysis, and calculation of intraclass correlation coefficients (ICCS). Unless otherwise stated, results are given on a per-lesion basis. Statistical analysis was done using R (Version 3.5.1) [19] or SPSS (SPSS Statistics, Version 25.0, IBM Corp., Armonk, NY, USA).

\section{Results}

A total of 83 lesions in 45 consecutive hematological patients with pulmonary nodules or masses diagnosed by routine clinical imaging were included in this study (24-76 years, median 59 years, 
16 female; 14 cases of acute myeloid leukemia, 4 cases of acute lymphocytic leukemia, 3 cases of chronic lymphocytic leukemia, 14 cases of B-cell non-Hodgkin lymphoma, 2 cases of T-cell nonHodgkin lymphoma, 7 cases of Hodgkin lymphoma, 1 case of severe anaplastic anemia). Imaging was performed because of suspected pulmonary infection in all cases. Except for two patients with bacterial pneumonia, all others had received a CT scan prior to the MRI examination (interval between imaging: 0-4 days, median 2 days).

Two patients with fungal pneumonia were not scanned because of their poor general condition. Two patients had to be excluded from the image analysis because of poor image quality: one patient with bacterial pneumonia and motion artifacts due to dyspnea and one patient with pulmonary lymphoma and unresolvable zipper artifacts. Two further patients were excluded from the analysis because the pulmonary findings could not be clearly attributed to the underlying lymphoma or an infection. Details are presented as a flowchart in $>$ Fig. 2 .

\section{Lesion analysis}

Data were not normally distributed. Median values of $T 1-Q_{\text {mean }}$ and T2-NICQ ${ }_{\text {mean }}$ differed significantly between the entities that were evaluated $(p<0.05)$. Median values of $T 2-N_{1 C Q} Q_{90 t h}$ were close to statistical significance $(p=0.054)$. Results are summarized in $>$ Table 1 and presented as boxplots in > Fig. 3a-c.

In the analysis of infectious lesions in general vs. lymphoma manifestations, the median values differed significantly for T2-NICQ ${ }_{\text {mean }}$ and T2-NICQ ${ }_{90 t h}$, but not for T1-Q $\mathrm{Q}_{\text {mean }}$. For bacterial pneumonias vs. lymphoma manifestations, the median values differed significantly for T2-NICQ ${ }_{\text {mean }}$ and T2-NICQ 90 th, but not for $\mathrm{T} 1-\mathrm{Q}_{\text {mean }}$. On the per-patient level, the median values differed significantly for T2-NICQ ${ }_{90 t h}$ only. For fungal lesions vs. lymphoma manifestations, the median values differed significantly for $\mathrm{T} 1-\mathrm{Q}_{\text {mean }}$ and $\mathrm{T} 2-\mathrm{NICQ} \mathrm{Q}_{\text {mean }}$, but not for $\mathrm{T} 2-\mathrm{NICQ}_{90 \mathrm{th}}$. On the per-patient level, the median values differed significantly for T2-NICQ ${ }_{\text {mean }}$ and T2-NICQ ${ }_{90 t h}$, but no longer for $\mathrm{T} 1-\mathrm{Q}_{\text {mean }}$. Details are provided in $>$ Table 1.

T2-NICQ ${ }_{\text {mean }}$ and T2-NICQ ${ }_{90 t h}$ showed the best areas under the curve (AUCs) for comparing infectious and fungal lesions vs. lymphoma manifestations. When comparing the per-lesion and the per-patient analysis, the results for $\mathrm{T} 1-\mathrm{Q}_{\text {mean }}$ differed only slightly while the AUCs of T2-NICQ on the per-patient level. A summary of the analysis is provided in

- Table 2.

\section{Inter- and intrarater reliability}

The interrater reliability was consistently excellent (ICC above 0.94). The intrarater reliability in general was lower, especially for T2-NICQs (T2-NICQ ${ }_{\text {mean }} 0.85$, T2-NICQ $\left._{90 t h} 0.79\right)$. However, the results were still good. Detailed results are compiled in $>$ Table 3.

\section{Discussion}

The current data confirm that NICQs are suitable parameters for differentiating infections from lymphoma manifestations, as

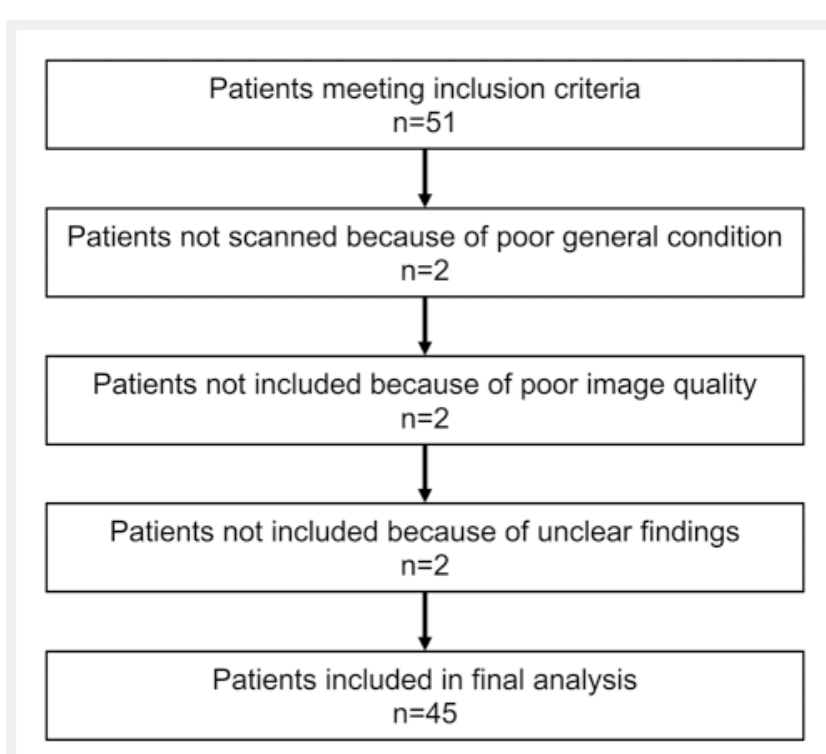

- Fig. 2 Flowchart of patients considered in this study. A total of 6 patients could not be included in the final analysis, with only two not being able to be examined due to their poor general condition.

- Abb. 2 Flussdiagramm der in dieser Studie betrachteten Patienten. Insgesamt 6 Patienten konnten nicht in die Analyse einbezogen werden, von denen nur 2 aufgrund ihres schlechten Allgemeinzustandes nicht untersucht werden konnten.

already suggested by the preliminary results by Nagel et al. [12]. Moreover, T1- $\mathrm{Q}_{\text {mean }}$, T2-NICQ ${ }_{\text {mean }}$, and T2-NICQ ${ }_{90 \text { th }}$ show almost consistently excellent inter- and intrarater reliability.

The results underline that especially $\mathrm{T} 2-\mathrm{NICQ}_{\text {mean }}$ and T2-NICQ ${ }_{90 t h}$ can be of help in distinguishing infectious lesions in general or fungal infiltrates in particular from pulmonary lymphoma manifestations. If findings still remain unclear, the quotients at least may help in the workup by providing early guidance for further diagnostics. Of note again is the simplicity of the approach, using fast standard sequences and easy to calculate parameters in the image assessment. The total scan time of approx. 12 minutes makes the protocol suitable for imaging critically ill patients [14].

Compared to a previous study in 29 patients that considered infectious vs. various malignant pulmonary nodules in general [12], the AUC of T1- $Q_{\text {mean }}, \mathrm{T} 2-\mathrm{NICQ}_{\text {mean }}$, and T2-NICQ 90 th on a per-lesion basis is lower in the present study when considering infections vs. lymphoma manifestations $\left(T 1-Q_{\text {mean }} 0.62\right.$ vs. 0.72 , T2-NICQ mean 0.66 vs. 0,73 , T2-NICQ ${ }_{90 t h} 0.65$ vs. 0.82 ). Nevertheless, regarding the critical issue of discriminating infections from pulmonary lymphoma manifestations in hematological patients, T2-NICQ ${ }_{\text {mean }}$ and T2-NICQ ${ }_{90 t h}$ showed promising results with an AUC of up to 0.76 with a specificity of up to 1.0 on a per-patient basis. Thus, the present findings confirm adequate diagnostic performance. It has to be noted that the number of lesions and patients evaluated mostly exceeds the numbers described in imaging-based thoracic diagnostic studies using MRI [8-11].

The concept of scaled signal intensities in MRI in general seems promising in the evaluation of pulmonary nodules. For example, 
- Table $1 \mathrm{~T} 1-\mathrm{Q}_{\text {mean }}, \mathrm{T} 2-\mathrm{NICQ}_{\text {mean }}$, and T2-NICQ ${ }_{90 \text { th }}$ of the analyzed pulmonary lesions.

- Tab. 1 T1- $\mathrm{Q}_{\text {mean }}, \mathrm{T}_{2}-\mathrm{NICQ}_{\text {mean }}$ und T2-NICQ90th der analysierten pulmonalen Läsionen.

\begin{tabular}{|c|c|c|c|c|}
\hline & & \multicolumn{3}{|l|}{ median } \\
\hline & & $\mathrm{T} 1-\mathrm{Q}_{\text {mean }}$ & T2-NICQ ${ }_{\text {mean }}$ & T2-NICQ ${ }_{90 \text { th }}$ \\
\hline \multirow[t]{4}{*}{ bacterial } & \multirow[t]{2}{*}{ lesions $(n=12)$} & 0.89 & 24.97 & 49.4 \\
\hline & & $0.78-1.02$ & $13.38-39.04$ & $23.47-72.43$ \\
\hline & \multirow[t]{2}{*}{ patients $(n=10)$} & 0.88 & 25.45 & 49.4 \\
\hline & & $0.76-1.02$ & $15.27-36.43$ & $24.98-78.03$ \\
\hline \multirow[t]{4}{*}{ fungal } & \multirow[t]{2}{*}{ lesions $(n=33)$} & 0.82 & 19.0 & 34.49 \\
\hline & & $0.68-0.91$ & $7.83-33.63$ & $21.0-63.93$ \\
\hline & \multirow[t]{2}{*}{ patients $(n=16)$} & 0.79 & 22.07 & 40.5 \\
\hline & & $0.71-0.94$ & $8.23-34.08$ & $20.46-64.57$ \\
\hline \multirow{4}{*}{$\begin{array}{l}\text { infectious } \\
\text { (bacterial + fungal) }\end{array}$} & \multirow[t]{2}{*}{ lesions $(n=45)$} & 0.84 & 20.33 & 34.96 \\
\hline & & $0.69-0.93$ & $8.37-34.52$ & $22.17-65.20$ \\
\hline & \multirow[t]{2}{*}{ patients $(n=36)$} & 0.85 & 22.43 & 44.65 \\
\hline & & $0.72-0.95$ & $12.24-34.52$ & $24.17-66.82$ \\
\hline \multirow[t]{4}{*}{ lymphoma } & \multirow[t]{2}{*}{ lesions $(n=38)$} & 0.89 & 10.14 & 25.52 \\
\hline & & $0.83-0.97$ & $2.03-22.57$ & $10.08-43.22$ \\
\hline & \multirow[t]{2}{*}{ patients $(n=19)$} & 0.9 & 8.88 & 22.4 \\
\hline & & $0.8-1.0$ & $2.03-15.85$ & $10.78-37.09$ \\
\hline \multirow[t]{2}{*}{ bacterial vs. lymphoma } & lesions & $p=0.95$ & $p<0.05$ & $\mathrm{p}<0.05$ \\
\hline & patients & $p=0.98$ & $P<0.05$ & $\mathrm{p}<0.05$ \\
\hline \multirow[t]{2}{*}{ fungal vs. lymphoma } & lesions & $p<0.05$ & $\mathrm{p}<0.05$ & $p=0.07$ \\
\hline & patients & $p=0.12$ & $\mathrm{p}<0.05$ & $p<0.05$ \\
\hline \multirow[t]{2}{*}{ infectious vs. lymphoma } & lesions & $p=0.06$ & $\mathrm{p}<0.05$ & $p<0.05$ \\
\hline & patients & $p=0.26$ & $p<0.005$ & $p<0.005$ \\
\hline \multicolumn{5}{|c|}{ 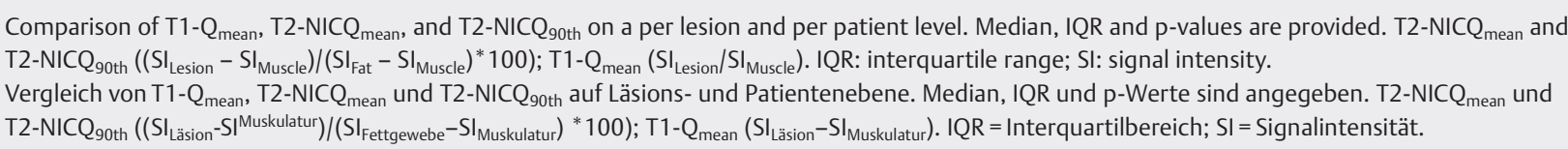 } \\
\hline
\end{tabular}

T1 and T2 values normalized to muscles correlated significantly with the standard uptake values (SUV) from PET/CT images in a study by $\mathrm{Koo}$ et al. that considered the differentiation of benign and malignant nodules [20]. In another study by Li et al., the qualitative assessment of the T1 and T2 signal intensity of nodules in relation to muscle and fat was used in the follow-up after cryoablation of lung tumors [21].

Future research might focus on the use of diffusion-weighted imaging (DWI), as it has been shown to be helpful in differentiating benign from malignant lesions in various studies [8, 9, 22-26]. Although this would prolong scanning time contrary to the concept of a strongly speed-optimized protocol, DWI also does not need iv contrast agents. Combining T1-Q $\mathrm{Q}_{\text {mean }}$ and T2-NICQs with DWI should therefore be evaluated, especially when motion correction for free-breathing acquisition is available to image critically ill patients.
The second aim of our study was to assess the reliability of NICQ measurement as a diagnostic tool. The intra- and interrater reliability was good to excellent with $T 1-Q_{\text {mean }}$ consistently showing the best results. Data on the inter- and intraobserver variability of NICQs have not been published before, so we can only speculate why ICCs are highest for T1-based measurement. One possible reason is that only two measurements are required and errors arising from a third measurement are avoided. In addition, a signal loss towards the center of the image was observed especially in T2w images. A possible explanation for this could be the use of surface coils and differences in the MR sequences: Gradient echo sequences are less susceptible to B1 inhomogeneities than fast spin echo sequences, which becomes more apparent at higher field strengths [27].

Thus, the obtained T1w images seem to provide more flexibility with respect to placing the ROI, which is represented by a 


\section{A}

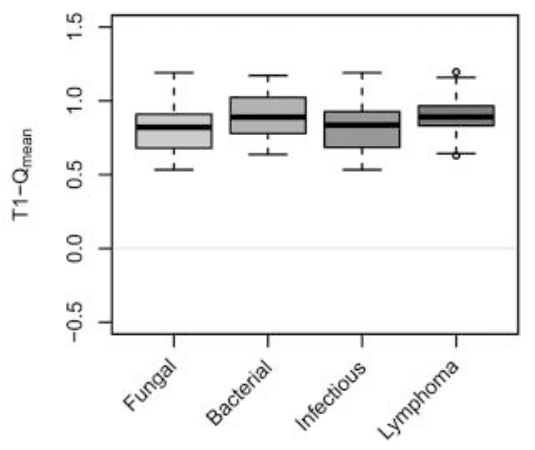

B

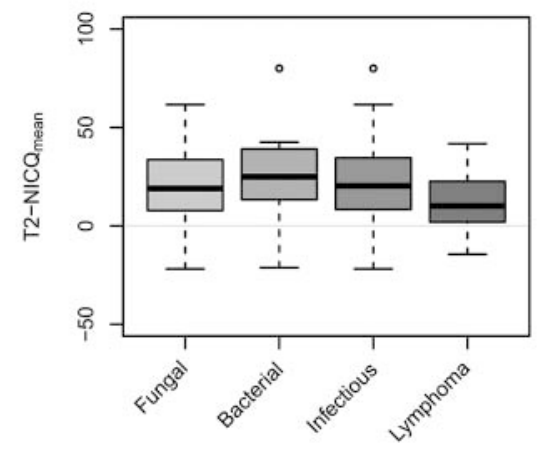

C

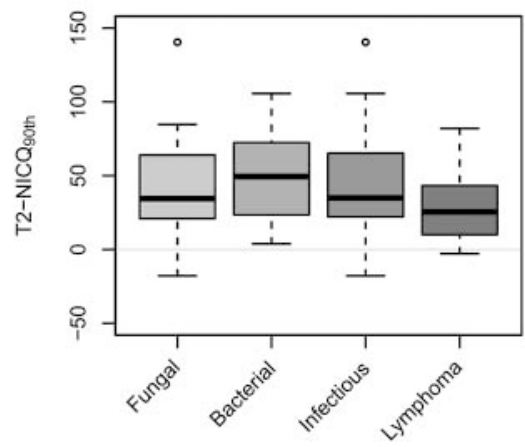

- Fig. 3 Boxplots comparing the signal intensity quotients $\mathrm{T} 1-\mathrm{Q}_{\text {mean }} \mathrm{A}, \mathrm{T} 2-\mathrm{NICQ}_{\text {mean }} \mathbf{B}$, and $\mathrm{T} 2-\mathrm{NICQ}_{90 \mathrm{th}} \mathbf{C}$. Infectious lesions in general and fungal infiltrates in particular were found to have higher T2 and lower T1 signal intensities. T2-NICQmean and T2-NICQ90th $\left(\left(\mathrm{SI}_{\text {Lesion }}-\mathrm{SI}_{\text {Muscle }}\right) /\left(\mathrm{SI}_{\text {Fat }}-\right.\right.$ $\left.\left.\mathrm{SI}_{\text {Muscle }}\right) * 100\right) ; \mathrm{T} 1-\mathrm{Q}_{\text {mean }}\left(\mathrm{SI}_{\text {Lesion }} / \mathrm{SI} \mathrm{I}_{\text {Muscle }}\right)$.

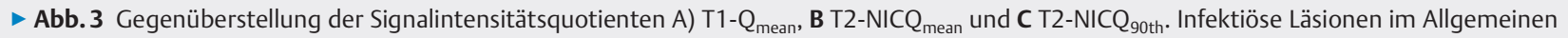
und Pilzinfiltrate im Besonderen zeigten höhere T2- und niedrigere T1-Signalintensitäten im Vergleich zu pulmonalen Lymphom-Manifestationen. T2-NICQmean und T2-NICQ 90 th $\left(\left(\mathrm{SI}_{\text {Läsion }}-\mathrm{SI}_{\text {Muskulatur }}\right) /\left(\mathrm{SI}_{\text {Fettgewebe }}-\mathrm{SI}_{\text {Muskulatur }}\right) * 100\right) ; \mathrm{T} 1-\mathrm{Q}_{\text {mean }}\left(\mathrm{SI}_{\text {Läsion }}-\mathrm{SI}_{\text {Muskulatur }}\right)$.

- Table 2 ROC analysis of T1- $\mathrm{Q}_{\text {mean }}, \mathrm{T}_{2}-\mathrm{NICQ}_{\text {mean }}$, and T2-NICQ ${ }_{90 \text { th }}$.

- Tab. 2 ROC-Analyse von T1- $\mathrm{Q}_{\text {mean }}, \mathrm{T}_{2}-\mathrm{NICQ}_{\text {mean }}$ und T2-NICQ 90 th.

\begin{tabular}{|c|c|c|c|c|c|c|c|}
\hline & & \multicolumn{3}{|l|}{ AUC } & \multicolumn{3}{|c|}{ optimal cut-off } \\
\hline & & $\mathrm{T} 1-\mathrm{Q}_{\text {mean }}$ & T2-NICQ & T2-NICQ 90 th & $\mathrm{T} 1-\mathrm{Q}_{\text {mean }}$ & T2-NICQ & T2-NICQ ${ }_{90 \text { th }}$ \\
\hline \multirow{4}{*}{$\begin{array}{l}\text { bacterial vs. } \\
\text { lymphoma }\end{array}$} & \multirow[t]{2}{*}{ lesions } & 0.49 & 0.71 & 0.71 & 0.73 & 28.99 & 52.68 \\
\hline & & $0.29-0.7, p=0.95$ & $0.52-0.9, p<0.05$ & $0.53-0.9, p<0.05$ & $0.25 / 0.87$ & $0.5 / 0.92$ & $0.5 / 0.92$ \\
\hline & \multirow[t]{2}{*}{ patients } & 0.51 & 0.79 & 0.79 & 0.76 & 16.78 & 31.98 \\
\hline & & $0.27-0.75, p=0.96$ & $0.59-0.99, p<0.05$ & $0.62-0.96, p<0.05$ & $0.3 / 0.9$ & $0.7 / 0.84$ & $0.7 / 0.74$ \\
\hline \multirow{4}{*}{$\begin{array}{l}\text { fungal vs. } \\
\text { lymphoma }\end{array}$} & \multirow[t]{2}{*}{ lesions } & 0.67 & 0.64 & 0.63 & 0.86 & 28.57 & 55.54 \\
\hline & & $0.54-0.8, p<0.05$ & $0.51-0.77, p<0.05$ & $0.49-0.76, p=0.07$ & $0.7 / 0.66$ & $0.36 / 0.92$ & $0.36 / 0.95$ \\
\hline & \multirow[t]{2}{*}{ patients } & 0.66 & 0.74 & 0.73 & 0.76 & 15.86 & 60.02 \\
\hline & & $0.47-0.85, p=0.11$ & $0.57-0.91, p<0.05$ & $0.56-0.9, p<0.05$ & $0.5 / 0.9$ & $0.69 / 0.79$ & $0.38 / 1$ \\
\hline \multirow{4}{*}{$\begin{array}{l}\text { infectious vs. } \\
\text { lymphoma }\end{array}$} & \multirow[t]{2}{*}{ lesions } & 0.62 & 0.66 & 0.65 & 0.86 & 28.57 & 55.54 \\
\hline & & $0.5-0.74, p=0.06$ & $0.54-0.77, p<0.05$ & $0.53-0.77, p<0.05$ & $0.62 / 0.66$ & $0.4 / 0.92$ & $0.38 / 0.95$ \\
\hline & \multirow[t]{2}{*}{ patients } & 0.6 & 0.76 & 0.75 & 0.76 & 16.77 & 60.02 \\
\hline & & $0.43-0.77, p=0.26$ & $0.62-0.9, p<0.005$ & $\begin{array}{l}0.61-0.89 \\
p<0.005\end{array}$ & $0.42 / 0.9$ & $0.65 / 0.84$ & $0.39 / 1$ \\
\hline
\end{tabular}

Analysis of T1- $\mathrm{Q}_{\text {mean }}$, $\mathrm{T} 2-\mathrm{NICQ}_{\text {mean }}$, and T2-NICQ ${ }_{90 \text { th }}$ on a per lesion and per patient level. AUCs, $95 \%$ confidence intervals and p-values are provided. AUC

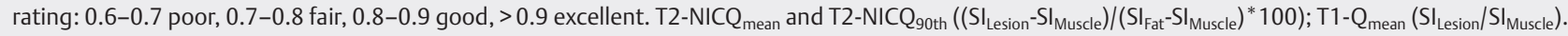
Optimal cutoffs were determined using Youden-Index; sensitivity and specificity are provided below. For T1- $\mathrm{Q}_{\text {mean }}$, values below the cutoff and for T2$\mathrm{NICQ}_{\text {mean }}$ and T2-NICQ ${ }_{90 t h}$ values above the cutoff indicate an infection. Please note the high specificity of T2-NICQs. ROC: receiver operator characteristic; AUC: area under the curve; SI: signal intensity.

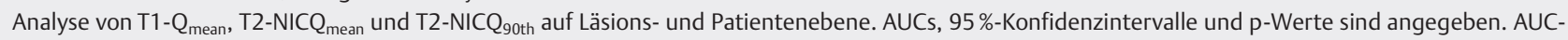

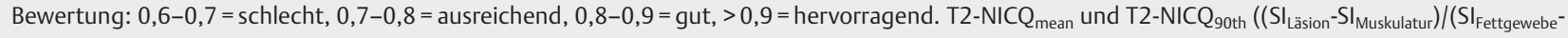
$\left.\left.\mathrm{SI}_{\text {Muskulatur }}\right) * 100\right) ; \mathrm{T} 1-\mathrm{Q}_{\text {mean }}\left(\mathrm{SI}_{\text {Läsion }}-\mathrm{SI} \mathrm{I}_{\text {Muskulatur }}\right.$ ). Optimale Cut-offs wurden unter Verwendung des Youden-Index bestimmt; Sensitivität/Spezifität werden

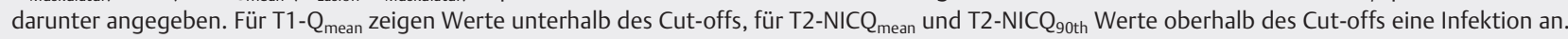
Man beachte die hohe Spezifität von T2-NICQs. ROC = receiver-operator-characteristic; $A U C=$ area under the curve; SI = Signalintensität 
- Table 3 Inter- and intrarater reliability of $\mathrm{T} 1-\mathrm{Q}_{\text {mean }}, \mathrm{T}_{2}-\mathrm{NICQ}_{\text {mean }}$, and T2-NICQ 90 th.

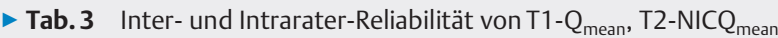
und T2-NICQ ${ }_{90 \text { th }}$.

\begin{tabular}{|l|l|l|}
\hline & interrater $(\mathbf{n}=\mathbf{8 3})$ & intrarater $(\mathbf{n}=\mathbf{2 4})$ \\
\hline \multirow{2}{*}{ T1- ${ }_{\text {mean }}$} & 0.97 & 0.93 \\
\cline { 2 - 3 } & $0.95-0.98, \mathrm{p}<0.001$ & $0.85-0.97, \mathrm{p}<0.001$ \\
\hline \multirow{2}{*}{ T2-NICQ } & 0.94 & 0.85 \\
\hline \multirow{2}{*}{ T2-NICQ } & $0.91-0.96, \mathrm{p}<0.001$ & $0.69-0.93, \mathrm{p}<0.001$ \\
\cline { 2 - 3 } & 0.95 & 0.79 \\
\hline & $0.93-0.97, \mathrm{p}<0.001$ & $0.58-0.9, \mathrm{p}<0.001$ \\
\hline
\end{tabular}

Interrater agreement calculated based on a mean rating $(k=2)$, absolute agreement, 2-way random-effects model. Intrarater agreement calculated based on a mean rating $(k=2)$, absolute agreement, 2-way mixedeffects model. ICC rating: $<0.50$ poor, $0.50-0.75$ moderate, $0.75-0.90$ good, $>0.90$ excellent. $T 1-Q_{\text {mean }}$ showed the best coefficients in both analyses. ICCs, $95 \%$ confidence intervals and p-values are provided. T2-NICQ ${ }_{\text {mean }}$ and T2-NICQ $Q_{90 \text { th }}\left(\left(\mathrm{SI}_{\text {Lesion }}-\mathrm{SI}_{\text {Muscle }}\right) /\left(\mathrm{SI}_{\text {Fat }}-\mathrm{SI}_{\text {Muscle }}\right) * 100\right)$; $\mathrm{T} 1-\mathrm{Q}_{\text {mean }}\left(\mathrm{SI} \mathrm{I}_{\text {Lesion }} / \mathrm{SI}\right.$ Muscle).

Interrater-Reliabilität, berechnet auf Grundlage der durchschnittlichen Wertung $(k=2)$, absoluten Übereinstimmung und eines 2-Wege-Zufallseffektmodells. Intrarater-Reliabilität, berechnet auf Grundlage der durchschnittlichen Wertung $(k=2)$, absoluten Übereinstimmung und eines 2-Wege-Mischeffektmodells. ICC-Bewertung: $<0,50,0,50-$ $0,75=$ moderat, $0,75-0,90=$ gut, $>0,90=$ ausgezeichnet. $T 1-Q_{\text {mean }}$ zeigte in beiden Analysen die besten Werte. ICCs, $95 \%$-Konfidenzintervalle und $\mathrm{p}$-Werte sind angegeben. T2-NICQ $\mathrm{Nean}_{\text {ma }}$ und $\mathrm{T}^{-\mathrm{NICQ}_{90 \text { th }}}$ $\left(\left(\mathrm{SI}_{\text {Läsion }}-\mathrm{S} \mathrm{I}_{\text {Muskulatur }}\right) /\left(\mathrm{SI}_{\text {Fettgewebe }}-\mathrm{SI} \mathrm{Muskulatur}\right)^{*} 100\right) ; \mathrm{T} 1-\mathrm{Q}_{\text {mean }}\left(\mathrm{SI}_{\text {Läsion }}{ }^{-}\right.$ $S \mathrm{I}_{\text {Muskulatur }}$.

smaller interquartile range of $\mathrm{T} 1-\mathrm{Q}_{\text {mean }}$. Nevertheless, the $\mathrm{T} 2 \mathrm{w}$ images of the scan time-optimized protocol used here are also suitable for reliable evaluation, especially for the identification of lymphoma lesions with low T2-NICQ.

In general, the use of a higher field strength when scanning the lung may lead to susceptibility effects at air-tissue interfaces [28]. In this regard, Fink et al. could show that the imaging characteristics did not substantially differ between 1.5 $\mathrm{T}$ and $3 \mathrm{~T}$ and furthermore, a better spatial resolution and a higher signal-to-noise and contrast-to-noise ratio can be expected [29]. The latter can be seen as a major advantage of higher field strengths, as the amount of protons to produce a signal is relatively low in the lungs [28].

Interestingly, the intrarater agreement was slightly inferior to the interrater agreement. A possible explanation may be the lower experience level of the second reader. Nevertheless, also the less experienced radiologist achieved at least good agreement in repeated measurements. Data on the inter- and intrarater variability of scaled signal intensity are currently not available. Theoretically, the inter- and intrarater variability might be enhanced by the use of mapping techniques, which would overcome the use of scaling regions [30]. However, using mapping techniques in a pulmonary setting might be limited by breathing artifacts resulting from the need to acquire different echo times for one image.

This study has some limitations. First, histopathologic proof was not available in all patients. Thus, clinical response to treatment was the only standard of reference available in some cases. We tried to compensate for this drawback by only including patients in whom the therapeutic response could be clearly attributed to the initiation of a new medication. Second, imaging quotients were evaluated without further consideration of clinical information. Taking additional data into account, e. g., laboratory results, may further enhance overall diagnostic performance. Thirdly, no follow-up studies were considered, although these are helpful in assessing pulmonary changes, especially infections. In addition, repeated scans in general could be one major strength of pulmonary MRI, as they do not require ionizing radiation.

In conclusion, the overall diagnostic performance of T2-NICQs is adequate for differentiating infectious and fungal lesions from lymphoma manifestations. Results further show good to excellent intra- and interrater agreement. We therefore consider NICQs helpful in the diagnostic workup of pulmonary nodules in hematological patients.

\section{CLINICAL RELEVANCE OF THE STUDY}

- Pulmonary MRI provides a noninvasive method for assessing pulmonary lesions in hematological patients by calculating Non-enhanced Imaging Characterization Quotients (NICQs).

- The quotients represent a pragmatic approach, as they are based on fast standard MRI sequences, do not require iv contrast and are easily calculated.

- With this simple approach, the quotients provide adequate diagnostic performance and good to excellent reliability.

\section{Conflict of Interest}

The authors declare that they have no conflict of interest.

\section{References}

[1] Ahuja J, Kanne JP. Thoracic infections in immunocompromised patients. Radiol Clin North Am 2014; 52: 121-136. doi:10.1016/j.rcl.2013.08.010

[2] Lee YR, Choi YW, Lee KJ et al. CT halo sign: the spectrum of pulmonary diseases. The British journal of radiology 2005; 78: 862-865. doi: $10.1259 / \mathrm{bjr} / 77712845$

[3] Tanaka N, Kunihiro Y, Yanagawa N. Infection in Immunocompromised Hosts: Imaging. J Thorac Imaging 2018; 33: 306-321. doi:10.1097| RTI.0000000000000342

[4] Cao Y, Shao C, Song Y. Analysis of the clinical features of invasive bronchopulmonary aspergillosis. Clin Respir J 2018; 12: 1635-1643. doi:10.1111/crj.12722

[5] Maschmeyer G, Haas A, Cornely OA. Invasive aspergillosis: epidemiology, diagnosis and management in immunocompromised patients. Drugs 2007; 67: 1567-1601

[6] Ruhnke M, Bohme A, Buchheidt D et al. Diagnosis of invasive fungal infections in hematology and oncology-guidelines from the Infectious 
Diseases Working Party in Haematology and Oncology of the German Society for Haematology and Oncology (AGIHO). Annals of oncology: official journal of the European Society for Medical Oncology / ESMO 2012; 23: 823-833. doi:10.1093/annonc/mdr407

[7] Seneviratna A, O'Carroll M, Lewis CA et al. Diagnostic yield of bronchoscopic sampling in febrile neutropenic patients with pulmonary infiltrate and haematological disorders. Intern Med J 2012; 42: 536-541. doi:10.1111/j.1445-5994.2011.02643.x

[8] Koyama H, Ohno Y, Seki S et al. Value of diffusion-weighted MR imaging using various parameters for assessment and characterization of solitary pulmonary nodules. European journal of radiology 2015; 84: 509-515. doi:10.1016/j.ejrad.2014.11.024

[9] Cakmak V, Ufuk F, Karabulut N. Diffusion-weighted MRI of pulmonary lesions: Comparison of apparent diffusion coefficient and lesion-tospinal cord signal intensity ratio in lesion characterization. Journal of magnetic resonance imaging: JMRI 2017; 45: 845-854. doi:10.1002/ jmri.25426

[10] Inan N, Arslan A, Donmez M et al. Diagnostic Accuracy of Dynamic Contrast Enhanced Magnetic Resonance Imaging in Characterizing Lung Masses. Iran J Radiol 2016; 13: e23026. doi:10.5812/iranjradiol.23026

[11] Chen L, Liu D, Zhang J et al. Free-breathing dynamic contrast-enhanced MRI for assessment of pulmonary lesions using golden-angle radial sparse parallel imaging. Journal of magnetic resonance imaging: JMRI 2018; 48: 459-468. doi:10.1002/jmri.25977

[12] Nagel SN, Kim D, Penzkofer T et al. Pulmonary MRI at 3T: Non-enhanced pulmonary magnetic resonance Imaging Characterization Quotients for differentiation of infectious and malignant lesions. European journal of radiology 2017; 89: 33-39. doi:10.1016/j.ejrad.2017.01.012

[13] De Pauw B, Walsh T], Donnelly JP et al. Revised definitions of invasive fungal disease from the European Organization for Research and Treatment of Cancer/Invasive Fungal Infections Cooperative Group and the National Institute of Allergy and Infectious Diseases Mycoses Study Group (EORTC/MSG) Consensus Group. Clinical infectious diseases: an official publication of the Infectious Diseases Society of America 2008; 46: 1813-1821. doi:10.1086/588660

[14] Nagel SN, Wyschkon S, Schwartz S et al. Can magnetic resonance imaging be an alternative to computed tomography in immunocompromised patients with suspected fungal infections? Feasibility of a speed optimized examination protocol at 3 Tesla. European journal of radiology 2016; 85: 857-863. doi:10.1016/j.ejrad.2016.02.009

[15] Biederer J, Beer M, Hirsch W et al. MRI of the lung (2/3). Why ... when ... how? Insights into imaging 2012; 3: 355-371. doi:10.1007/s13244011-0146-8

[16] Attenberger UI, Morelli JN, Henzler T et al. 3Tesla proton MRI for the diagnosis of pneumonia/lung infiltrates in neutropenic patients with acute myeloid leukemia: Initial results in comparison to HRCT. European journal of radiology 2014; 83: e61-e66. doi:10.1016/j.ejrad.2013.09.002

[17] Fedorov A, Beichel R, Kalpathy-Cramer J et al. 3D Slicer as an image computing platform for the Quantitative Imaging Network. Magnetic resonance imaging 2012; 30: 1323-1341. doi:10.1016/ j.mri.2012.05.001

[18] Park H, Yoon SW, Sokolov A. Scaled signal intensity of uterine fibroids based on T2-weighted MR images: a potential objective method to determine the suitability for magnetic resonance-guided focused ultrasound surgery of uterine fibroids. European radiology 2015; 25: 34553458. doi:10.1007/s00330-015-3806-0

[19] R Development Core Team. R: A language and environment for statistical computing. In: R Foundation for Statistical Computing 2016

[20] Koo CW, Lu A, Takahashi EA et al. Can MRI contribute to pulmonary nodule analysis? Journal of magnetic resonance imaging: JMRI 2018. doi:10.1002/jmri.26587

[21] Li ], Qu J, Zhang $\mathrm{H}$ et al. 3.0T MRI for long-term observation of lung nodules post cryoablation: a pilot study. Cancer imaging: the official publication of the International Cancer Imaging Society 2017; 17: 29. doi:10.1186/s40644-017-0131-7

[22] Zhang F, Zhou Z, Tang D et al. Diffusion-weighted MRI in solitary pulmonary lesions: associations between apparent diffusion coefficient and multiple histopathological parameters. Sci Rep 2018; 8: 11248. doi:10.1038/s41598-018-29534-z

[23] Çakır Ç, Gençhellaç H, Temizöz O et al. Diffusion Weighted Magnetic Resonance Imaging for the Characterization of Solitary Pulmonary Lesions. Balkan Med J 2015; 32: 403-409. doi:10.5152/balkanmedj.2015.15663

[24] Kurihara Y, Matsuoka S, Yamashiro T et al. MRI of pulmonary nodules. Am J Roentgenol American journal of roentgenology 2014; 202: W210W216. doi:10.2214/Am J Roentgenol.13.11618

[25] Guan HX, Pan YY, Wang Y] et al. Comparison of Various Parameters of DWI in Distinguishing Solitary Pulmonary Nodules. Curr Med Sci 2018; 38: 920-924. doi:10.1007/s11596-018-1963-5

[26] Tyagi N, Cloutier M, Zakian K et al. Diffusion-weighted MRI of the lung at 3T evaluated using echo-planar-based and single-shot turbo spin-echobased acquisition techniques for radiotherapy applications. J Appl Clin Med Phys 2018. doi:10.1002/acm2.12493

[27] Ibrahim TS, Lee R, Abduljalil AM et al. Dielectric resonances and B(1) field inhomogeneity in UHFMRI: computational analysis and experimental findings. Magnetic resonance imaging 2001; 19: 219-226

[28] Wild JM, Marshall H, Bock M et al. MRI of the lung (1/3): methods. Insights into imaging 2012; 3: 345-353. doi:10.1007/s13244-012-0176-x

[29] Fink C, Puderbach M, Biederer J et al. Lung MRI at 1.5 and 3 Tesla: observer preference study and lesion contrast using five different pulse sequences. Investigative radiology 2007; 42: 377-383. doi:10.1097| 01.rli.0000261926.86278.96

[30] Roller FC, Fuest S, Meyer M et al. Assessment of Cardiac Involvement in Fabry Disease (FD) with Native T1 Mapping. RoFo: Fortschritte auf dem Gebiete der Rontgenstrahlen und der Nuklearmedizin 2019. doi:10.1055/a-0836-2723 